\section{E-Learning in Asia: Supply and Demand}

\section{Alan Olsen}

Alan Olsen is director of strategy policy and research in education in Singapore and Sydney. E-mail: Alan.Olsen@spre.com.sg.

$\mathrm{F}$ ew data are available on the demand for electronically delivered higher education, or e-higher education. Market research findings tend to be held tightly by market researchers and their clients. Data are available in the public domain about demand for higher education, and its supply, enabling a less direct exploration of demand for e-higher education.

\section{Global Demand for Higher Education}

In 1995, IDP Education Australia modeled the global demand for higher education. Changes in population and in participation rates are the two drivers of growth in demand. Looking ahead to 2025, growth in participation rates is the major contributor to growth in demand. As per capita incomes increase, so do participation rates: as incomes rise, demand for higher education grows. Global demand for higher education was projected to grow over the years 1990 to 2025, at the unsurprising rate of 3.5 percent per year.

Demand was forecast to grow from 48 million enrollments in 1990 to 159 million enrollments in 2025. Demand from Africa was expected to grow from 2 million to 15 million and demand from Asia from 17 million to 87 million. Of the increase of 111 million, 70 million would occur in Asia. The 1995 figures now look conservative. More recent modeling suggests that by 2020 China will be unable to supply the 20 million university places needed to meet the demands of its developing economy, and that in the long term the demand for international education in China will far exceed the capacity of the global education industry to provide enrollments. Similarly, in 2015 India will be unable to supply 9 million university places.

These bleak forecasts of unmet demand have been made at a time of growing reluctance on the part of governments globally to fund the increasing demand for higher education.

Global demand for higher education was projected to grow over the years 1990 to 2025, at the unsurprising rate of 3.5 percent per year.
Supply of Higher Education On-line

On-line delivery ought to be able to supply higher education to meet much of this unmet global demand. However, a number of barriers exist: cost, access to technology, mismatch of levels, and the lack of a quality assurance framework. How can these barriers be addressed?

In terms of cost, a new generation of distance education has the potential to deliver a quantum leap in economies of scale and associated cost-effectiveness, and to increase access to learning opportunities on a global scale.

As described at the University of Southern Queensland, in Australia, the Intelligent Flexible Learning Model provides interactive multimedia on-line, involves Internet-based access to www resources, uses automated response systems for computer-mediated communication and offers campus portal access to institutional processes and resources. The model scans the text of incoming electronic queries and responds intelligently. It is flexible with respect to time, place, and pace. Critically, institutional variable costs approach zero.

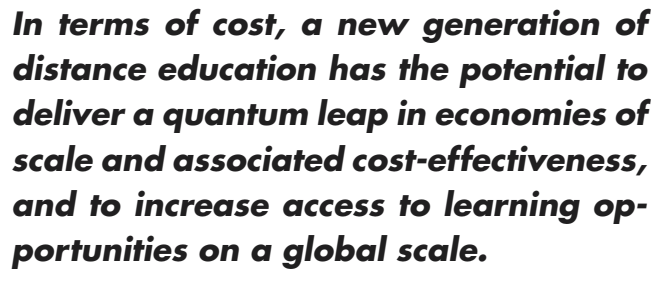

The issue with access to technology is that, just as a technology approaches mainstream status in developing countries (radio, television) and becomes feasible as a medium for distance learning, other technologies (Internet) emerge that are further out of reach in these countries.

The African Virtual University (AVU) is committed to multimode delivery, including the use of videotapebased courses delivered by satellite, web-based courses, $\mathrm{CD}-\mathrm{ROMs}$ and interactive sessions, using the Internet. AVU uses learning centers, each equipped with a satellite dish for receiving signals, large screen projectors, at least 50 computers, Internet access, e-mail, fax, and telephone services. On-site moderators guide the learning process.

The DIRECWAY Global Education initiative in India brings together franchisees to operate classrooms or learning centers, satellite delivery from a central studio to a transceiver connected to a local area network of personal computers, and the Apollo Group's track record in the United States in bringing education to working 
adults.

In terms of mismatch of levels, debate about unmet demand focuses on undergraduate places, yet much of the supply of international on-line higher education involves postgraduate courses. Presumably, market research shows that it is students seeking postgraduate courses who have the ability to pay.

At the UK e-University, a newly established initiative, the first courses will be at the postgraduate level. The continuous market research by Universitas Global appears to be pointing to a business model involving postgraduate courses.

Similarly, a national survey at Australian universities in 2001 found that 90 percent of "fully on-line" courses were postgraduate. Yet this does not reflect the shape of flexible provision in Australia. In 2000, 64 percent of the Australian students in flexible learning programs and 59 percent of the international students in these programs were undergraduates.

With convergence of modes of delivery, flexible learning is being used to enable a university to teach its standard profile. Once enough universities offer their standard profiles on-line, the dominance of postgraduate on-line course offerings will be seen as an aberration.

With regard to the lack of a quality assurance framework, the yearning is for an international quality framework to ensure that foreign students can be confident that they are getting a quality higher education.

\section{Presumably, market research shows that it is students seeking postgraduate courses who have the ability to pay.}

The Observatory on Borderless Higher Education describes genuine borderlessness: a U.K. university providing a degree on-line through a U.K. private company, utilizing a portal in Singapore and a support center in Bahrain. It would be an interesting global quality assurance and accreditation framework that encompasses such an example of on-line higher education.

Responsibility for quality assurance must be on the provider to ensure that the on-line program is at least equivalent in standard to the same program at the home institution, to ensure that the program is effective in achieving its educational objectives (the common test of quality), to have in place a quality assurance system, and to commission independent third party evaluations of its on-line programs.
Responsibility for quality assurance must be on the provider to ensure that the on-line program is at least equivalent in standard to the same program at the home institution.

\section{Conclusion}

Universities see new technologies as providing delivery to any student, anywhere, at any time. Flexible delivery is being used as much to solve on-campus problems as to provide off-campus access. Face-to-face, distance, and open learning modes of delivery are converging, and the boundaries between these modes are blurring. The demand for e-higher education is seen as a subset of demand for higher education. Perhaps more accurately, on-line delivery is a mode for supplying higher education. In this context, there is logic in the extent to which e-learning is being supply driven by institutions.

This article is based on the report E-Learning in Asia: Supply and Demand, prepared by Alan Olsen for the Observatory on Borderless Higher Education, www.obhe.ac.uk.

\section{Cost Sharing and Higher Education Access in Southern and Eastern Africa \\ Bruce Johnstone and Pamela Marcucci}

D. Bruce Johnstone is University Professor of Higher and Comparative Education at the State University of New York at Buffalo, and director of the Center for Comparative and Global Studies in Education. Pamela Marcucci is project manager for the Center's International Comparative Higher Education Finance and Accessibility Project. Address: Comparative and Global Education Center, Baldy Hall, SUNY-Buffalo, Buffalo, NY 14260, USA. E-mail: <DBJ@buffalo.edu>.

A 10-nation conference, "Financing Higher Education in Eastern and Southern Africa: Diversifying Revenue and Expanding Accessibility," was held in Dar es Salaam, Tanzania, in March 2002, cohosted by the University of Dar es Salaam and the International Comparative Higher Education Finance and Accessibility Project of the State University of New York at Buffalo. The conference was funded by the Ford Foundation. The full report of the conference is available on the website of the University at Buffalo Project at: http:// www.gse.buffalo.edu/org/IntHigherEdFinance/. The following article is based on this conference. 